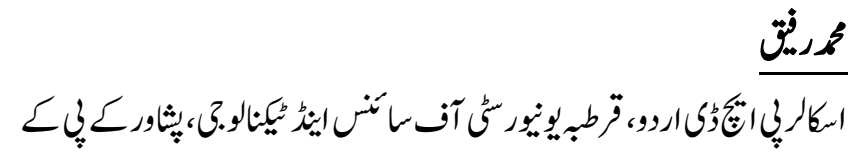

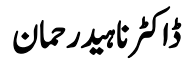

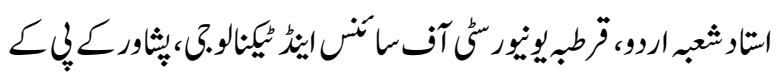

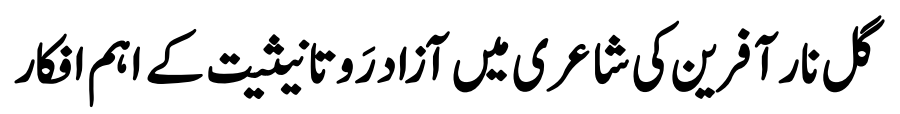

Muhammad Rafiq

Scholar Ph.D Urdu, Qurtuba University of Science and Information Technology Peshawar, KPK.

Dr. Naheed Rehman

Department of Urdu, Qurtuba University of Science and Information Technology Peshawar, KPK.

\title{
Main Liberal Feministic Approaches in Gul Nar Afareen's Poetry
}

The article covers fundamental ideas of Liberal Feminism that have been depicted by Urdu Poetess namely Gul Naar Aafreen. She has been impressed by the concepts of political autonomy and freedom. She has reflected Feminist problems such as Honor killing, Economic, Legal, Political and social rights of Pakistani women, who have been fallen victim to terrorism, Social oppression, Gender differences, Social stereotypes and Old customs.

Key Words: Feminist Individualism, Political Autonomy, Fonor Killing, Liberal Feminism, Oppression, Stereotypes.

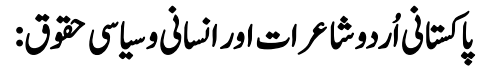

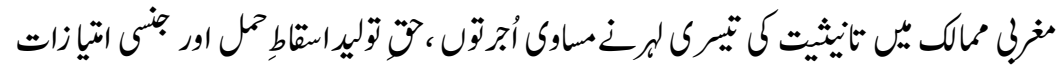

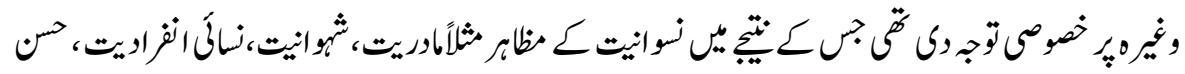

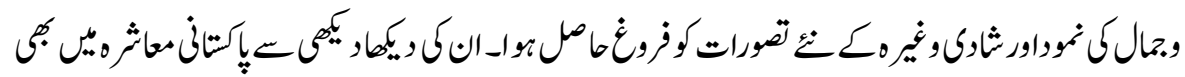

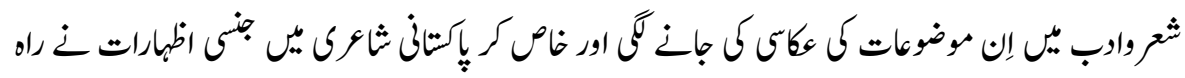

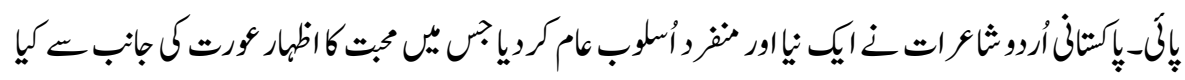




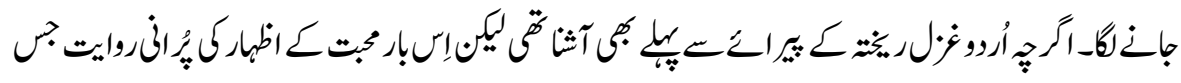

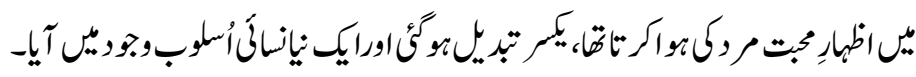

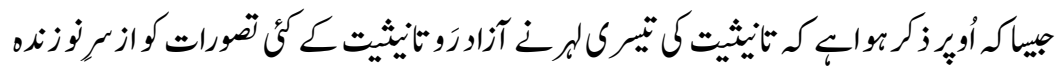

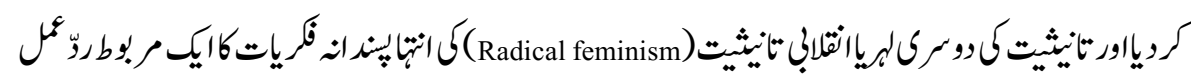

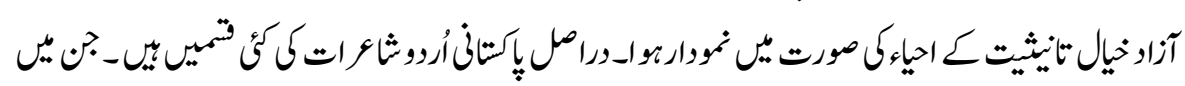

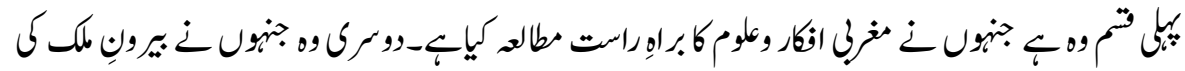

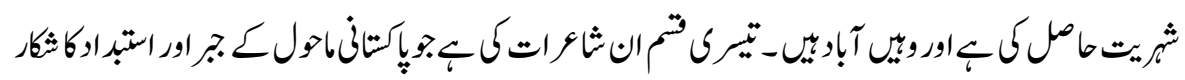

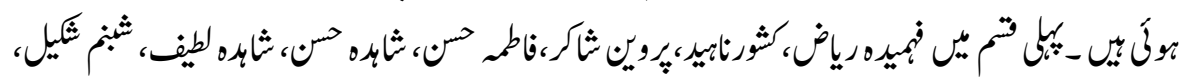

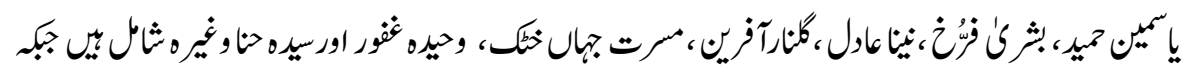

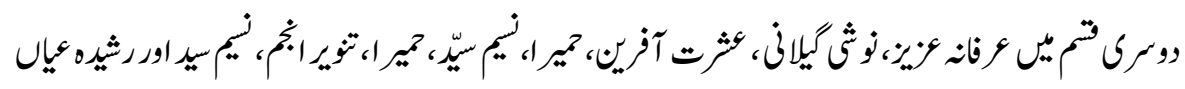

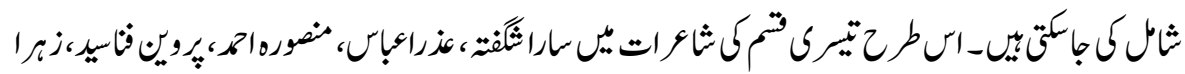

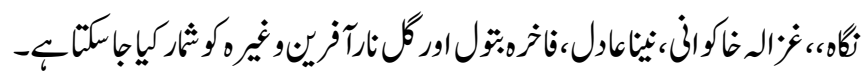

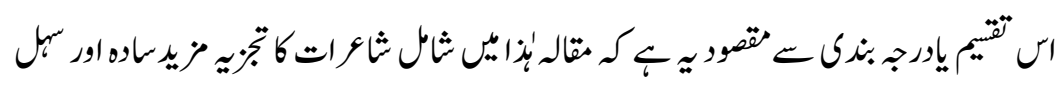

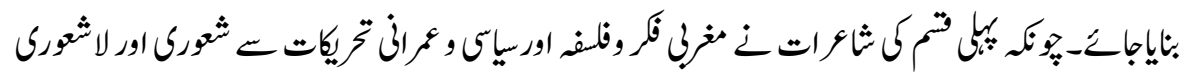

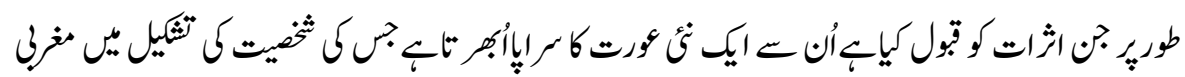

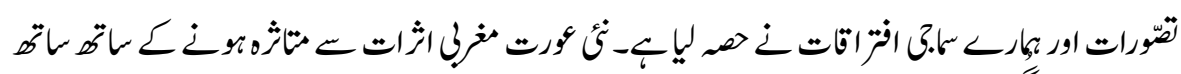

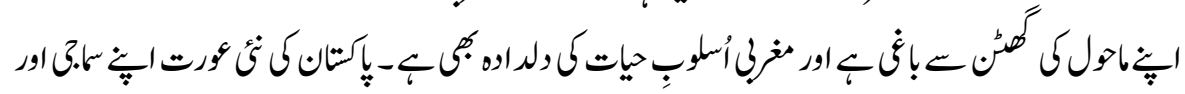

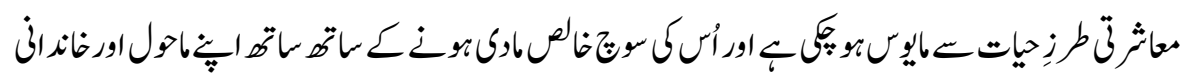

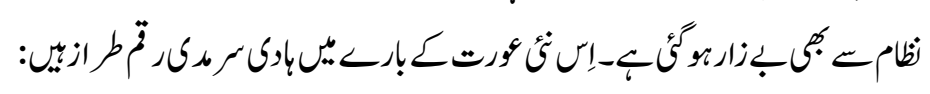

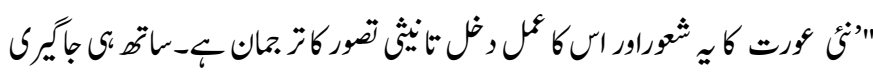

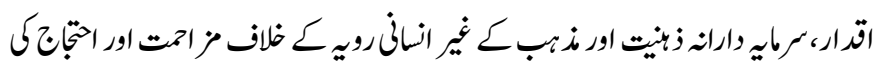

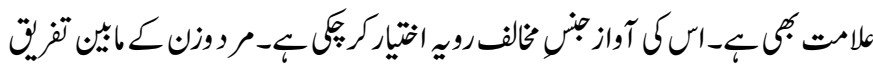

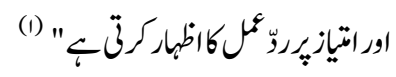




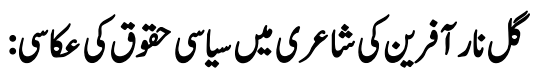

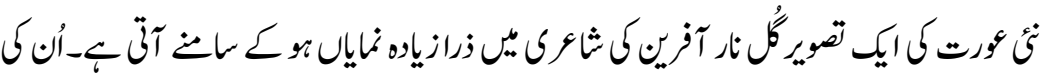

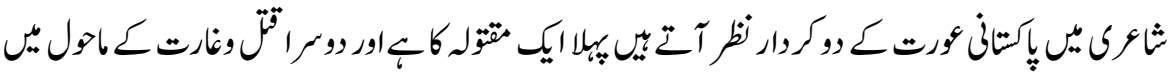

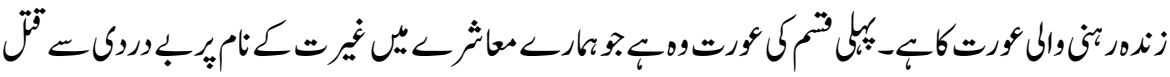

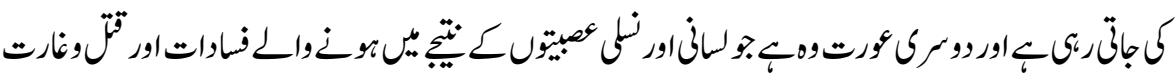

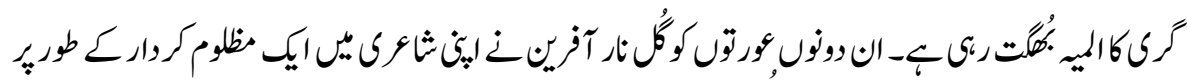

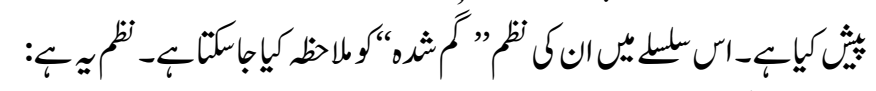

كمثره

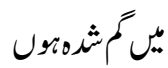

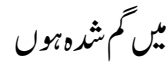

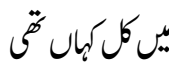

"ي

ئن:

$$
\text { يامكئيون }
$$

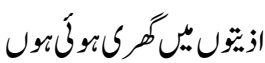

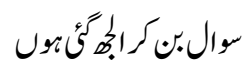

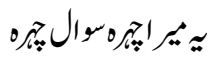

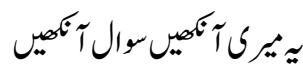

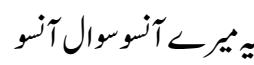

يميركانيس عزابهانيس

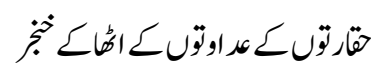

بونباياير انيفونزاريكي

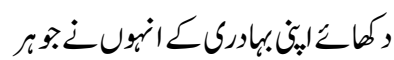

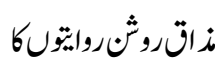




$$
\begin{aligned}
& \text { عقيرتوك } \\
& \text { كب: } \\
& \text { الرانـواس }
\end{aligned}
$$

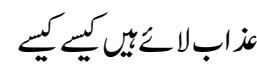

$$
\begin{aligned}
& \text { ترولك مقتل سجاسنواس }
\end{aligned}
$$

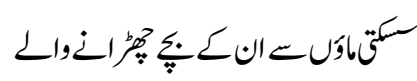

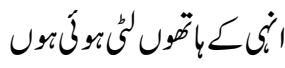

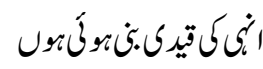

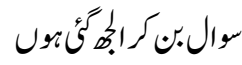

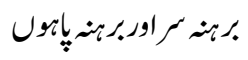

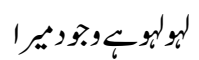

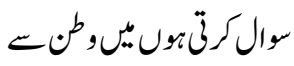

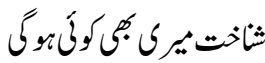

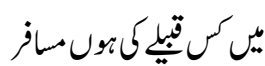

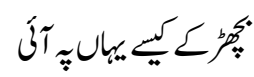

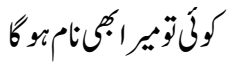

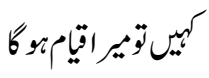

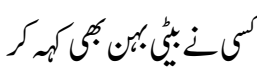

$$
\begin{aligned}
& 6 \text { 6 } 6
\end{aligned}
$$

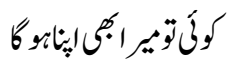

$$
\begin{aligned}
& \text { تمامرثتول كوكويكي كول } \\
& \text { ثمارنغون }
\end{aligned}
$$

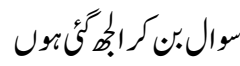

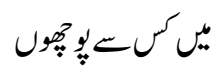

$$
\begin{aligned}
& \text { ين يَّ بانون }
\end{aligned}
$$




$$
\begin{aligned}
& \text { 1. }
\end{aligned}
$$

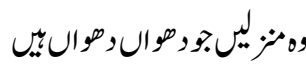

$$
\begin{aligned}
& \text { وهون بيلاور } \\
& \text { Zآ }
\end{aligned}
$$

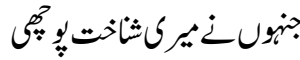

$$
\begin{aligned}
& \text { وبوريم امطأنإِإ }
\end{aligned}
$$

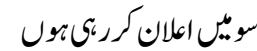

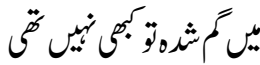

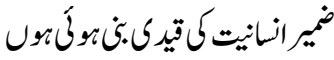

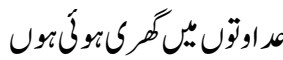

$$
\begin{aligned}
& \text { ror) }
\end{aligned}
$$

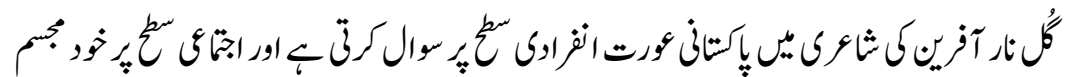

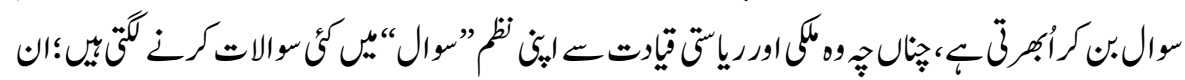

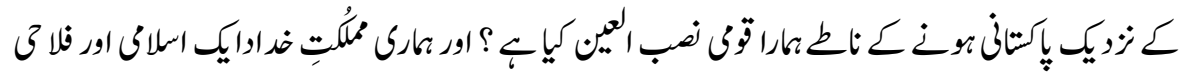

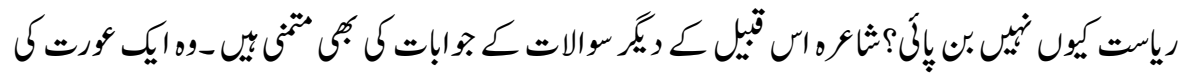

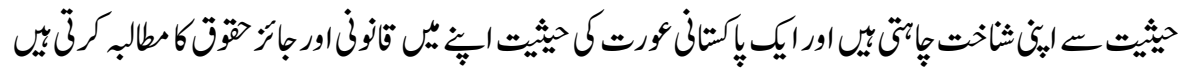

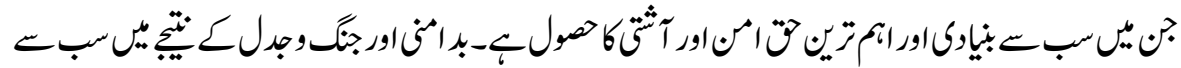

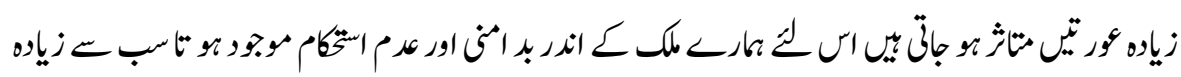

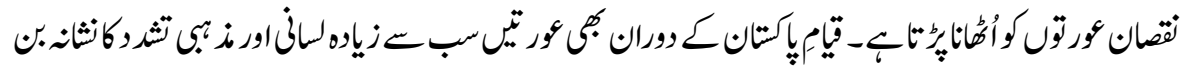

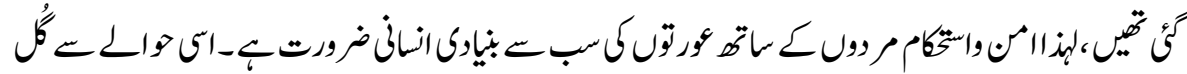

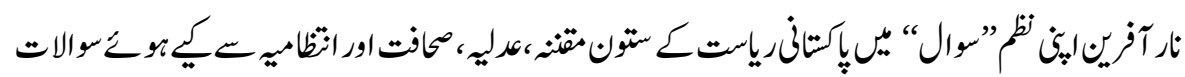

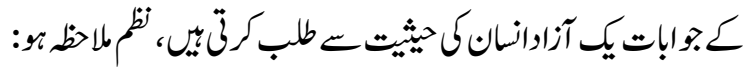

$$
\begin{aligned}
& \text { rوال }
\end{aligned}
$$

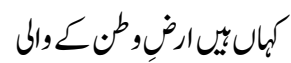




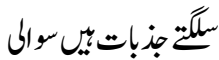

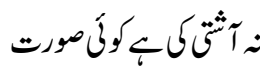

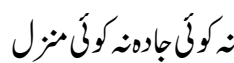

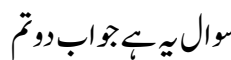

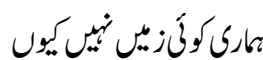

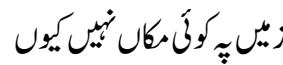

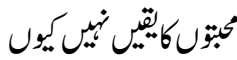

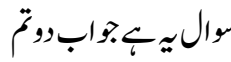

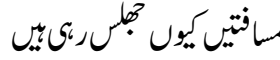

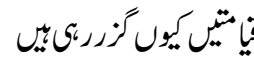

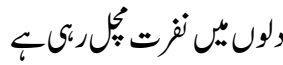

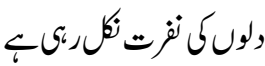

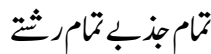

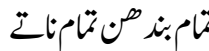

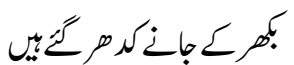

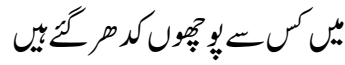

$$
\begin{aligned}
& \text { سانقوكالموالييك }
\end{aligned}
$$

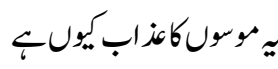

$$
\begin{aligned}
& \text { ير }
\end{aligned}
$$

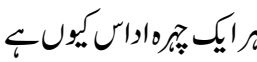

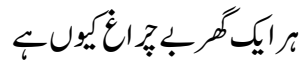

$$
\begin{aligned}
& \text { قرمقرمبه بوت ارزال } \\
& \text { " }
\end{aligned}
$$

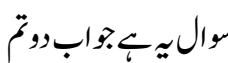

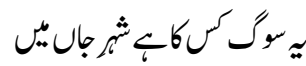




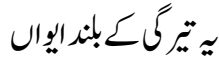

$$
\begin{aligned}
& \text { منازتكابر تص جنيس }
\end{aligned}
$$

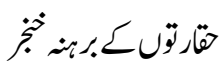

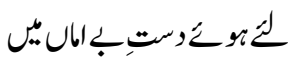

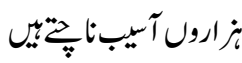

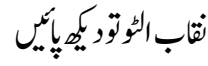

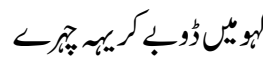

$$
\begin{aligned}
& \text { زان سارايجانتاك }
\end{aligned}
$$

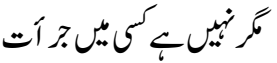

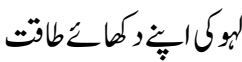

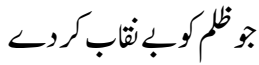

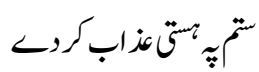

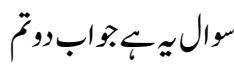

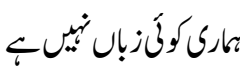

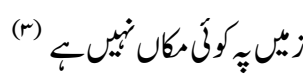

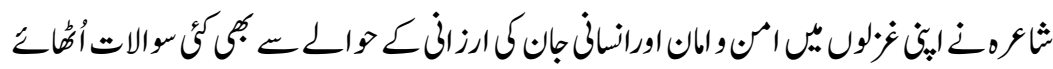

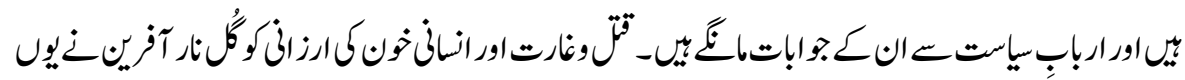

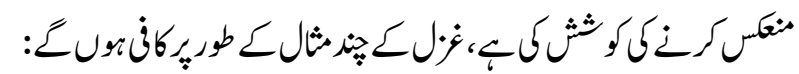

$$
\text { C }
$$

$(r)$

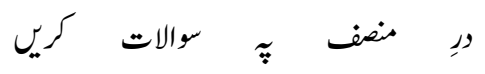

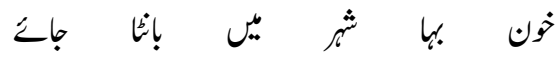

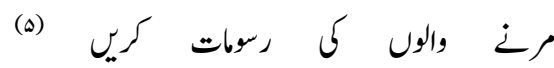

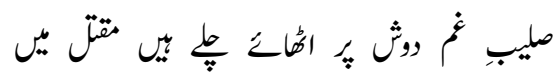

(4)

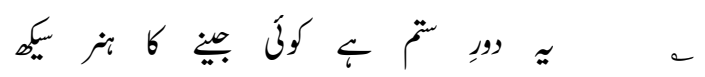




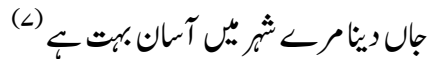

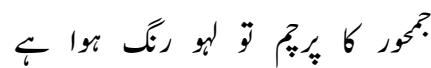

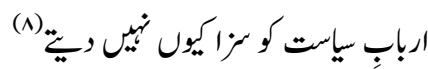

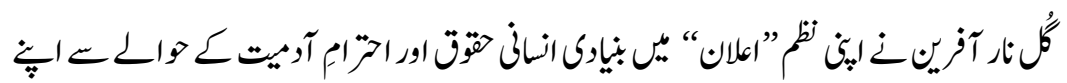

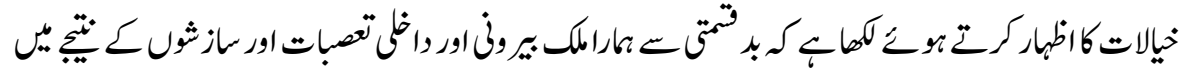

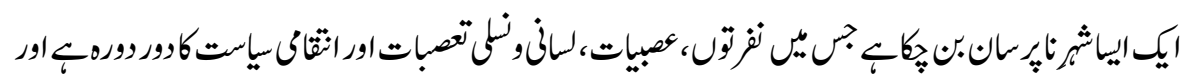

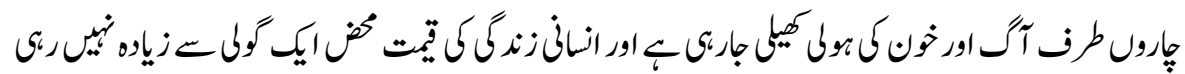

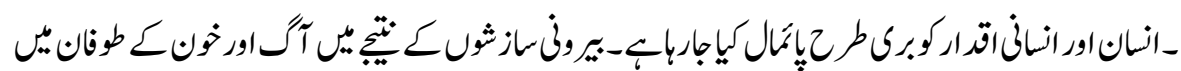

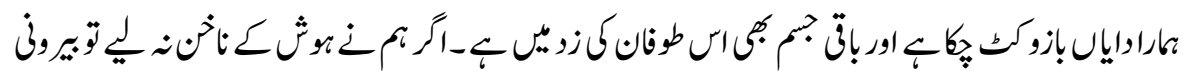

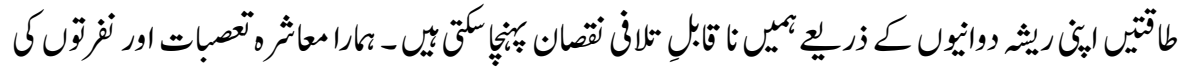

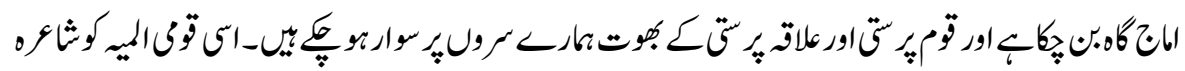

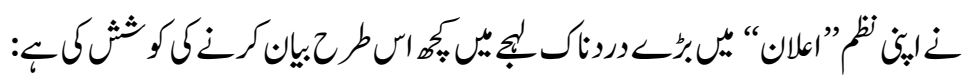

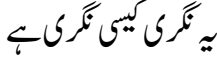

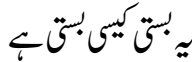

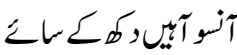

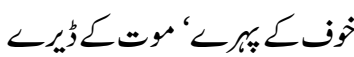

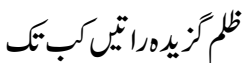

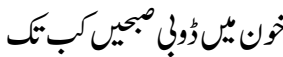

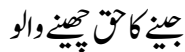

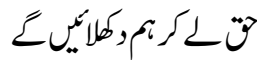

$$
\begin{aligned}
& \text { روك سكوتوروك بيكمو }
\end{aligned}
$$

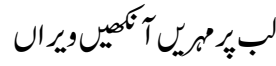

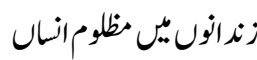




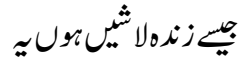

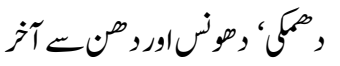

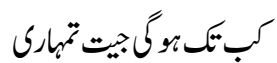

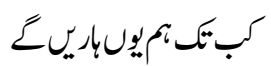

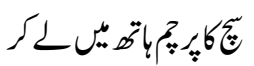

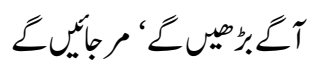

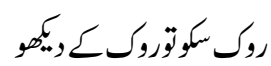

$$
\begin{aligned}
& \text { كمركماتمبو كاكبتك } \\
& \text { رمكريلبينياكبتك } \\
& \text { ظلم ك آع عبكاكبتك }
\end{aligned}
$$

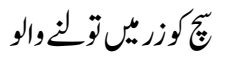

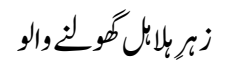

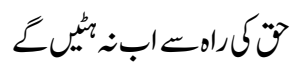

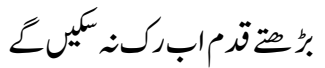

$$
\begin{aligned}
& \text { روكسكوتروك كيميمو }
\end{aligned}
$$

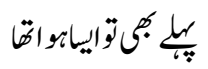

$$
\begin{aligned}
& \text { انسورقكوثون ويايتا } \\
& \text { كن لوي اعلانيمارا }
\end{aligned}
$$

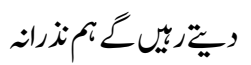

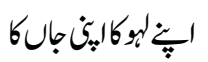

$$
\begin{aligned}
& \text { روك سكو تزروك ليسيمو (9) }
\end{aligned}
$$

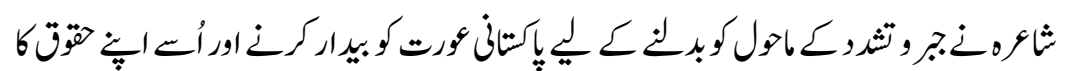

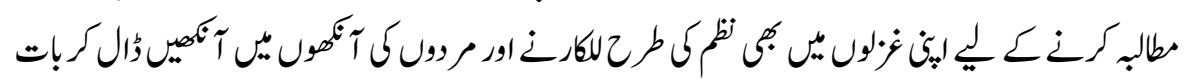

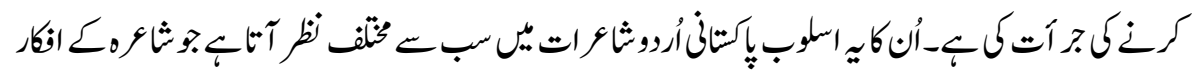




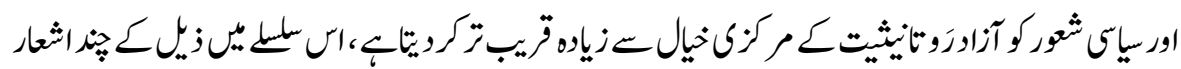

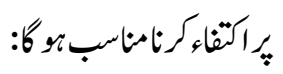

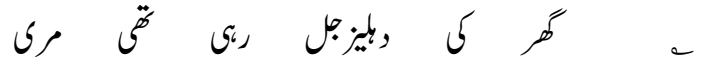

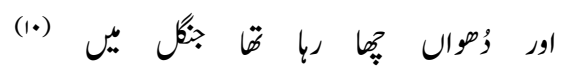

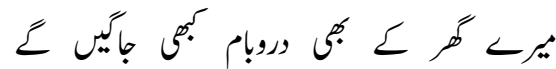

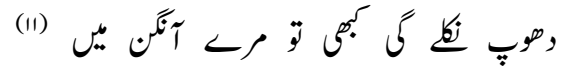

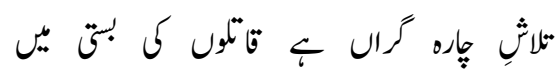

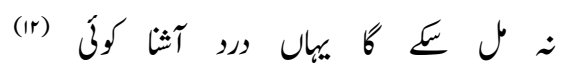

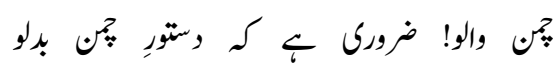

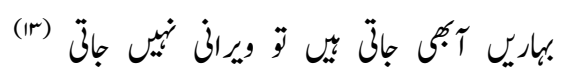

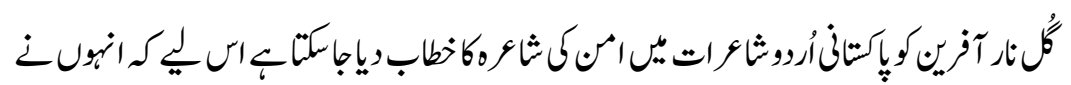

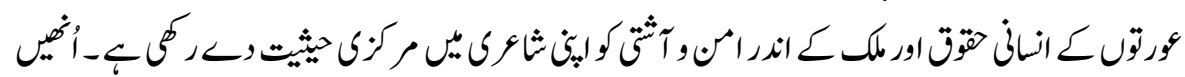

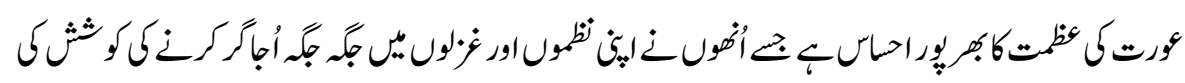

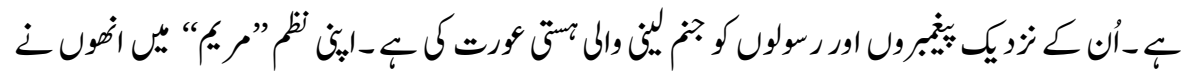

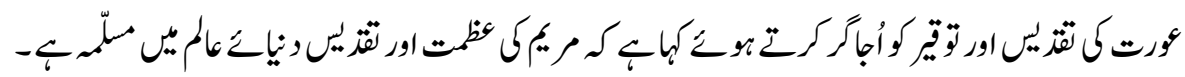

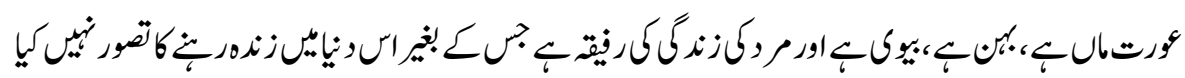

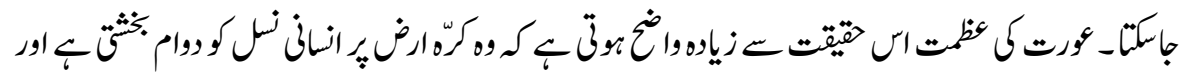

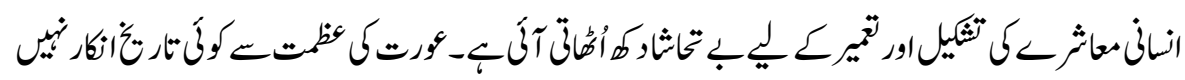

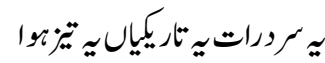

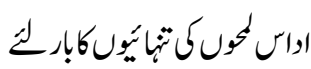

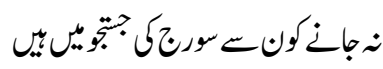

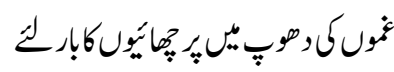




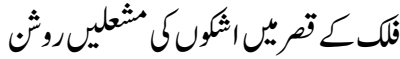

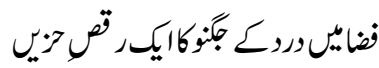

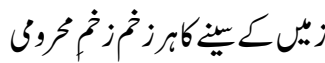

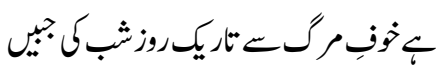

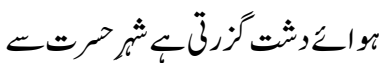

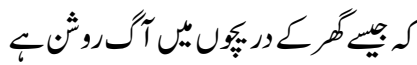

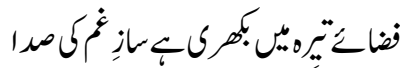

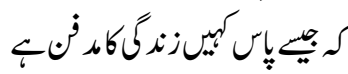

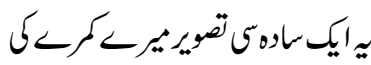

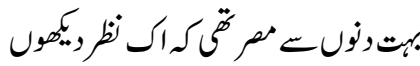

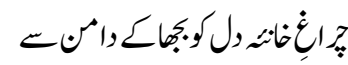

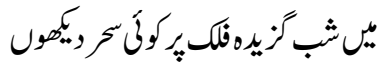

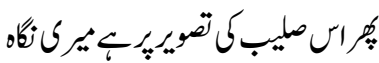

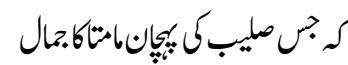

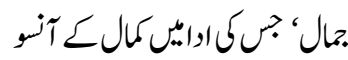

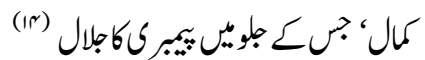

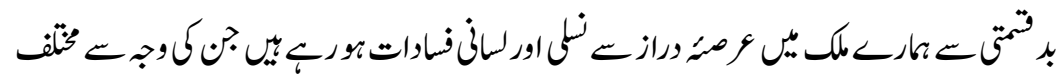

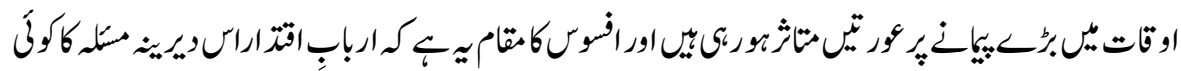

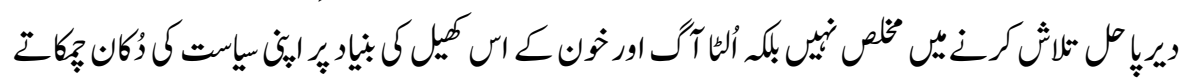

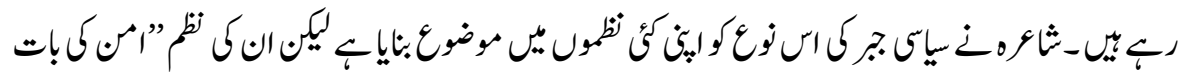

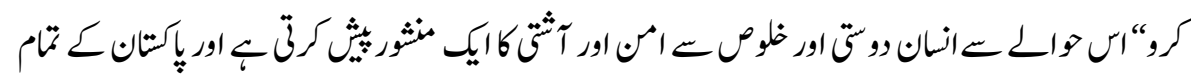

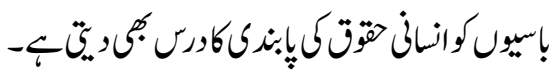

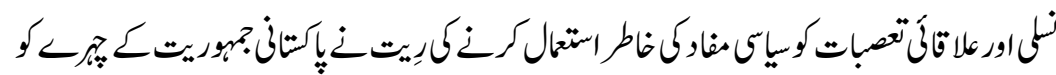

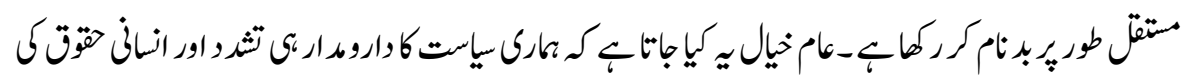




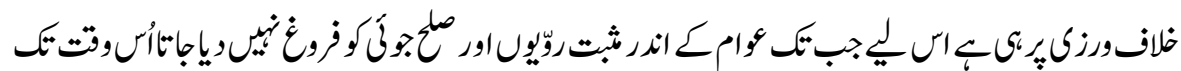

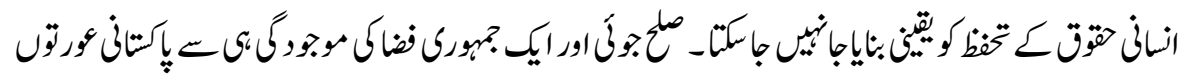

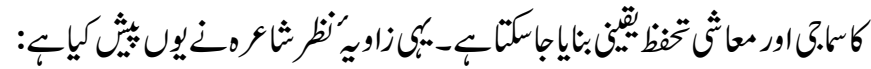

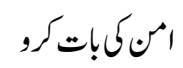

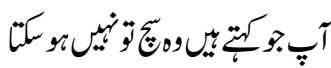

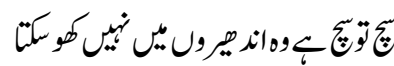

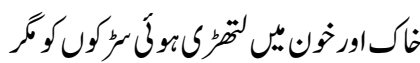

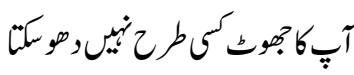

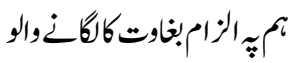

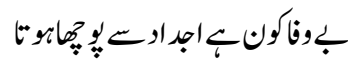

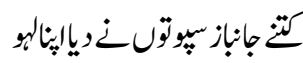

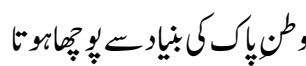

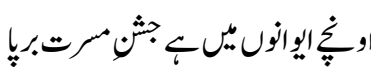

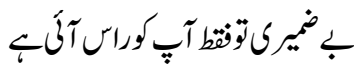

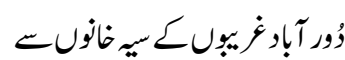

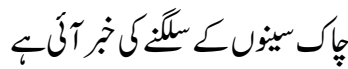

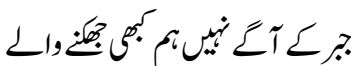

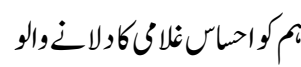

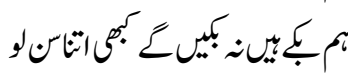

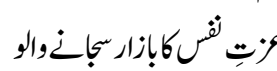

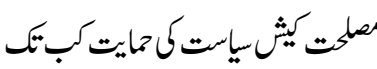

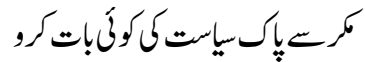

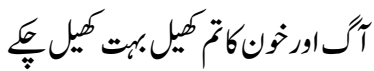

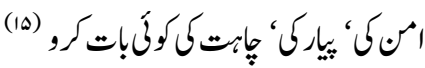




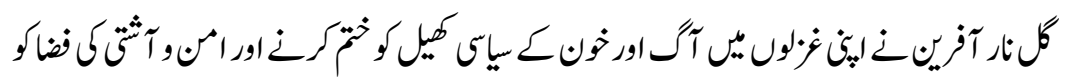

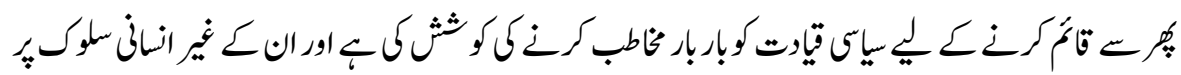

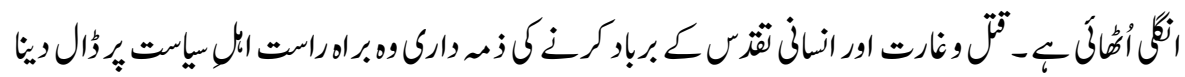

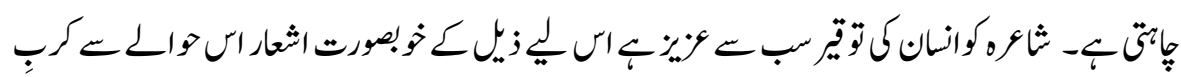

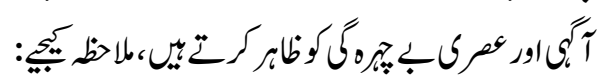
(14)

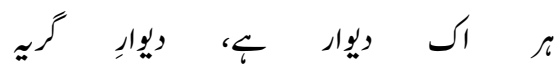

(1L) إن

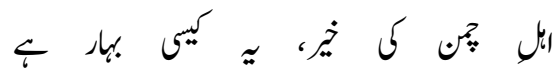

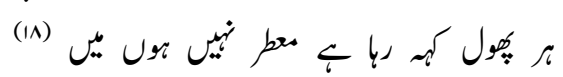

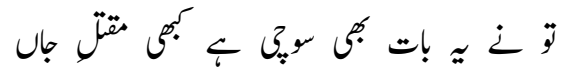

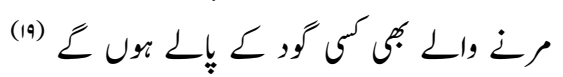
هابره

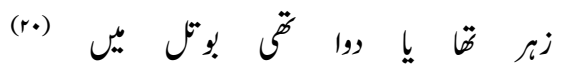

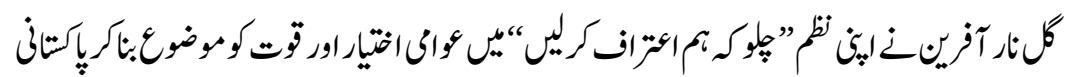

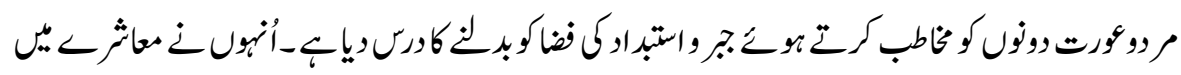

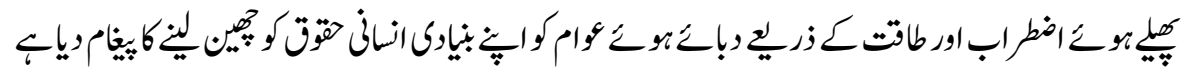

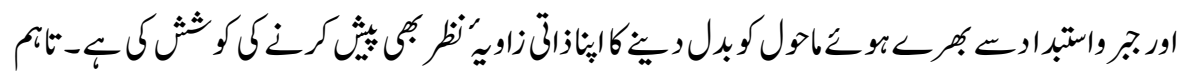

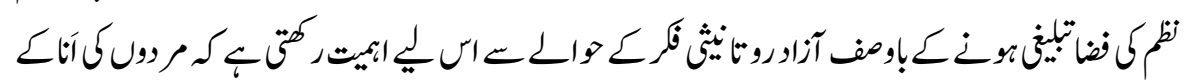

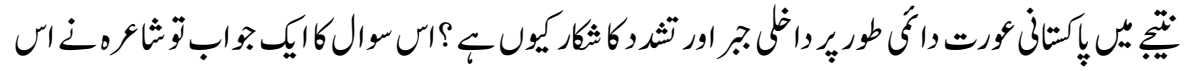

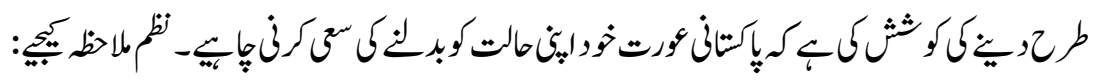

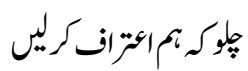

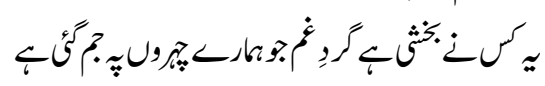




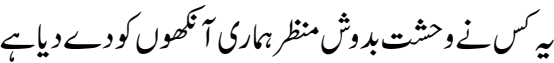

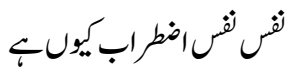

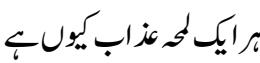

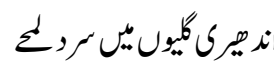

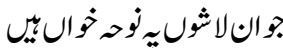

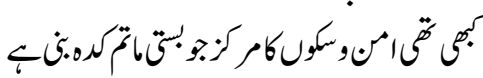

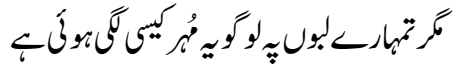

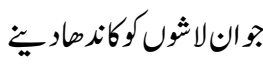

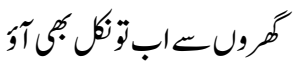

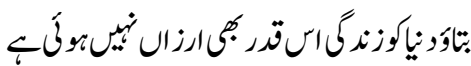

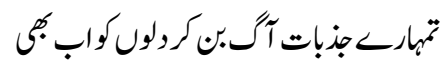

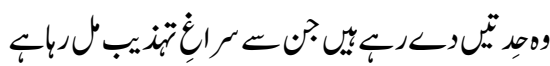

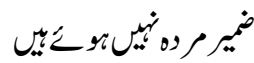

$$
\begin{aligned}
& \text { | ازيونكاثركرك }
\end{aligned}
$$

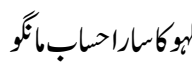

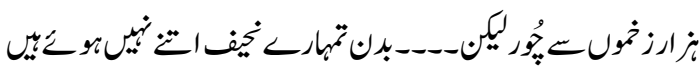

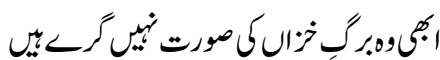

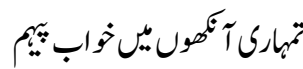

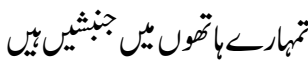

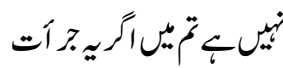

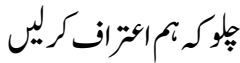

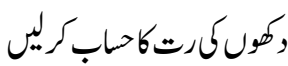

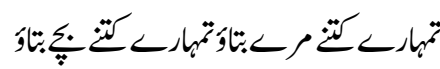

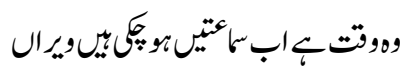

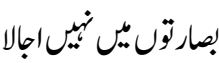




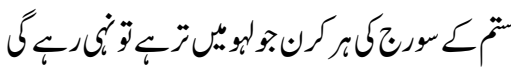

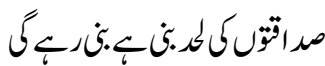

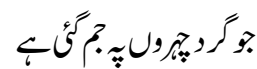

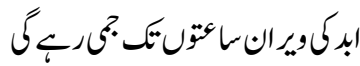

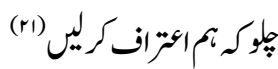

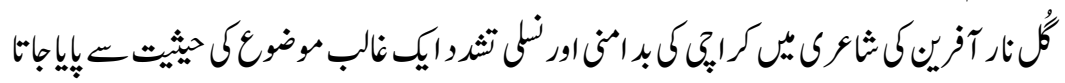

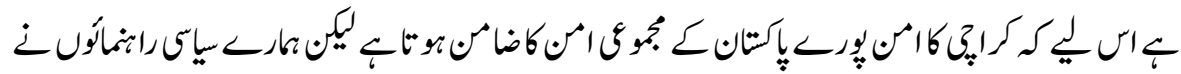

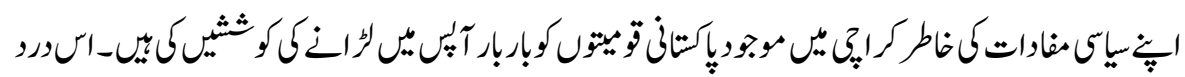

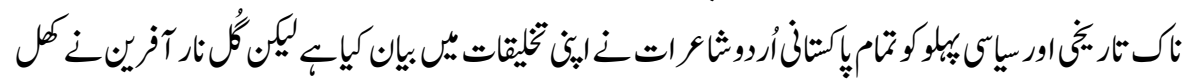

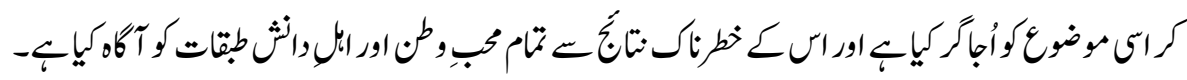

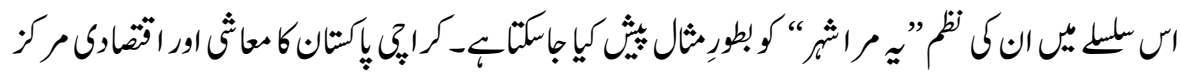

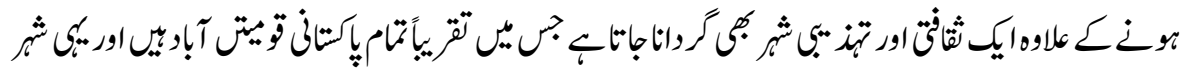

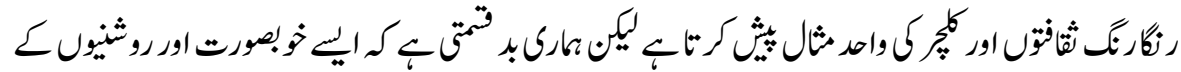

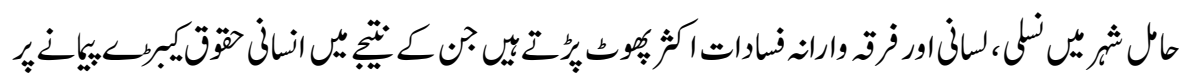

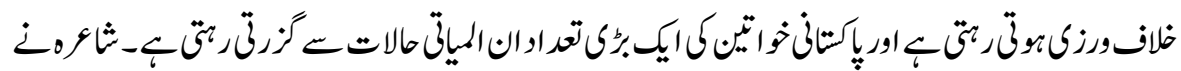

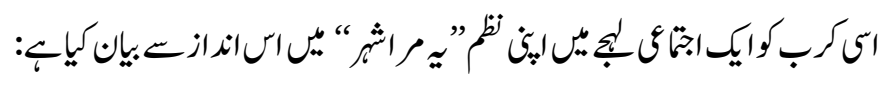

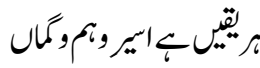

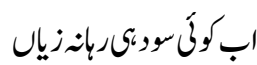

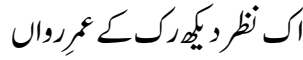

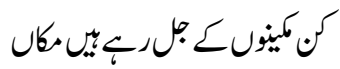

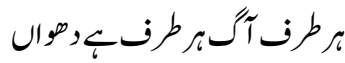

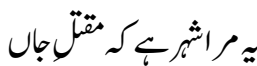

$$
\begin{aligned}
& \text { هإكساحساكريان }
\end{aligned}
$$




$$
\begin{aligned}
& \text { ثاير انوليموترثمالك }
\end{aligned}
$$

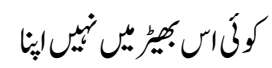

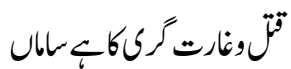

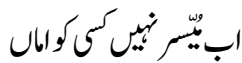

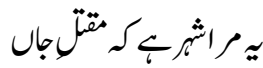

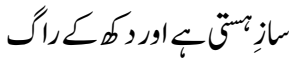

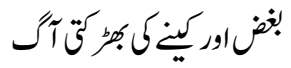

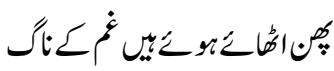

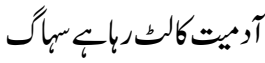

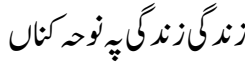

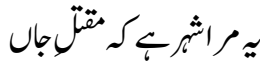

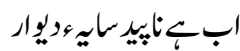

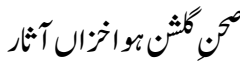

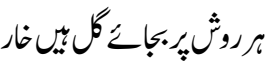

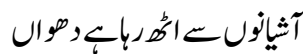

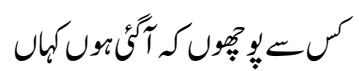

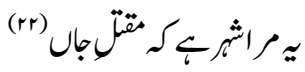

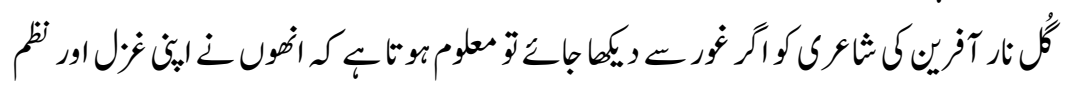

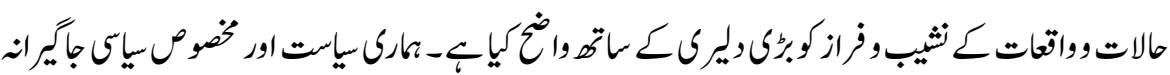

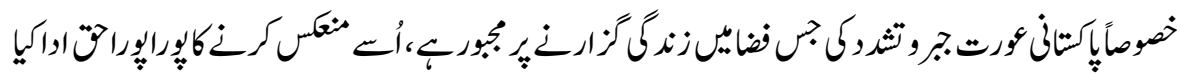

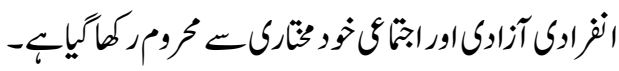

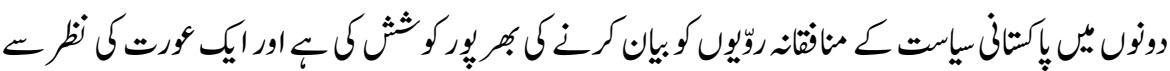

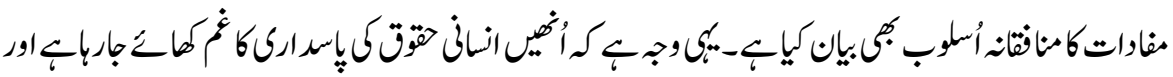

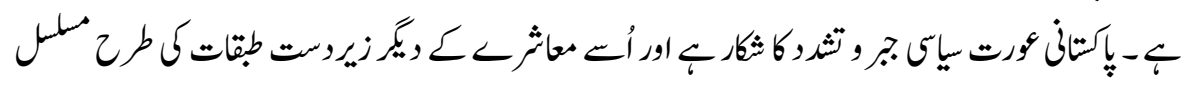




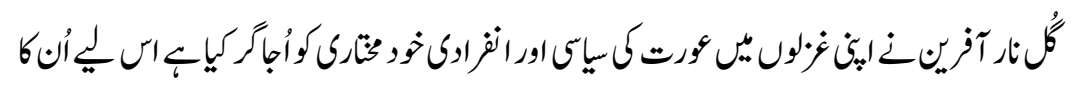

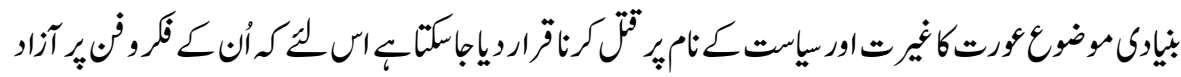

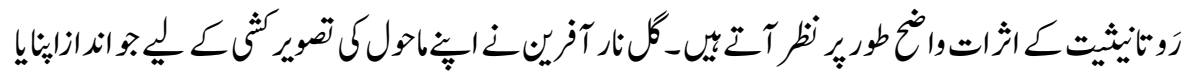

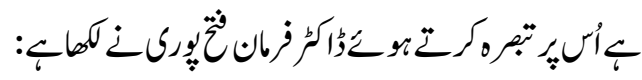

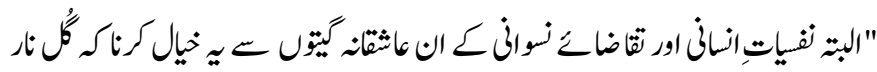

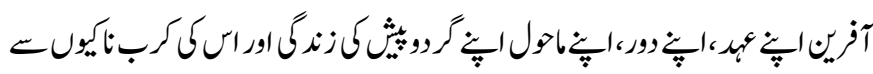

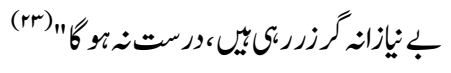

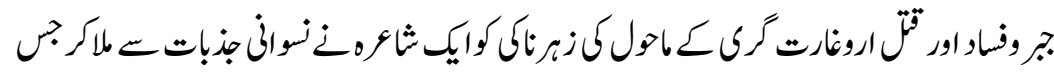

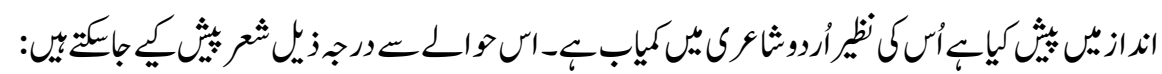

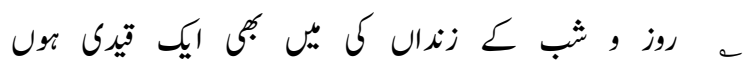

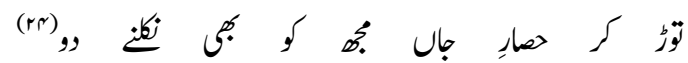

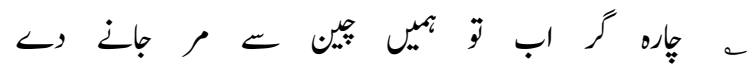

نز

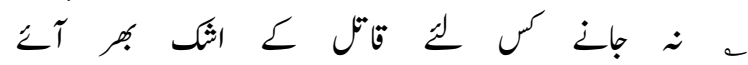

زَرِ

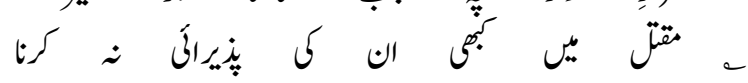

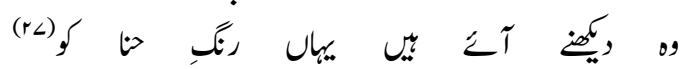

2

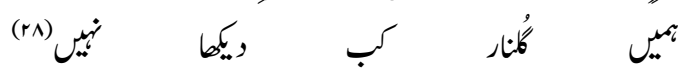

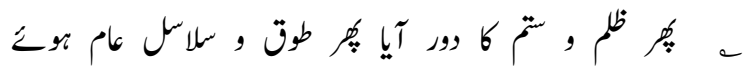

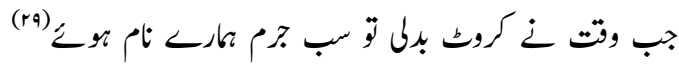

\section{والرجات}

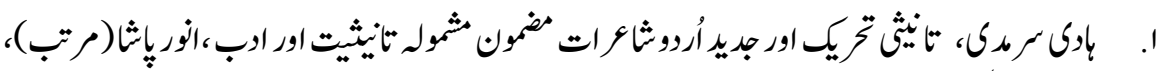

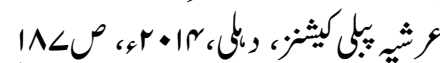

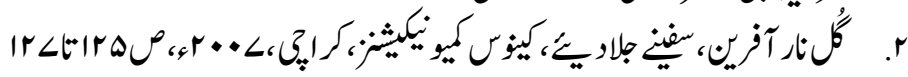




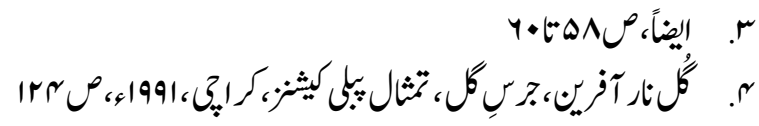

$$
\begin{aligned}
& \text { ه. اليضاً، صrri } \\
& \text { 4. اليضاً، ص4ry }
\end{aligned}
$$

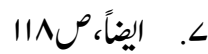

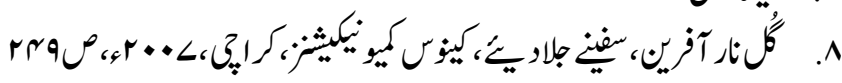

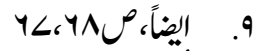

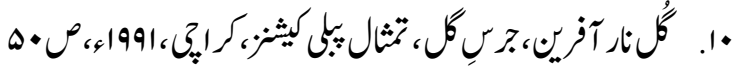

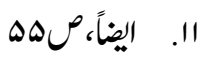

$$
\begin{aligned}
& \text { rا. اليضا، ص4 }
\end{aligned}
$$

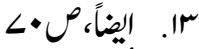

$$
\begin{aligned}
& \text { rr }
\end{aligned}
$$

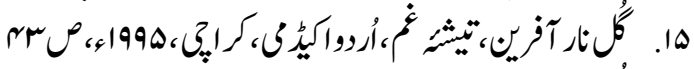

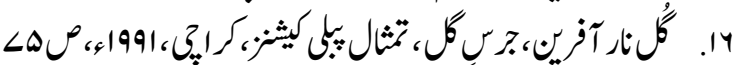

$$
\begin{aligned}
& \text { عا. اليضاً، }
\end{aligned}
$$

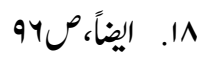

$$
\begin{aligned}
& \text { 19. إيضاً، ص r. } \\
& \text { •r. اليضاً، ص. }
\end{aligned}
$$

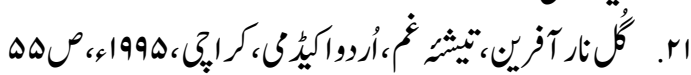

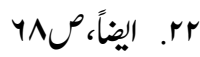

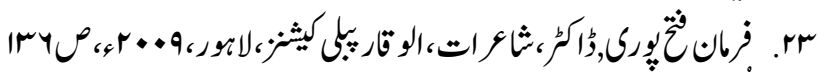

$$
\begin{aligned}
& \text { هrr } \\
& \text { מ.r. اليضاً، ص<م } \\
& \text { r (ry }
\end{aligned}
$$

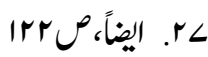

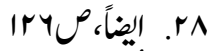

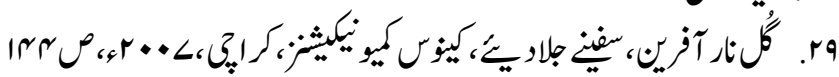

